Anja Klein

\title{
Geschichte und Gebet
}

\author{
Die Rezeption der biblischen Geschichte in den Psalmen des Alten Testaments
}

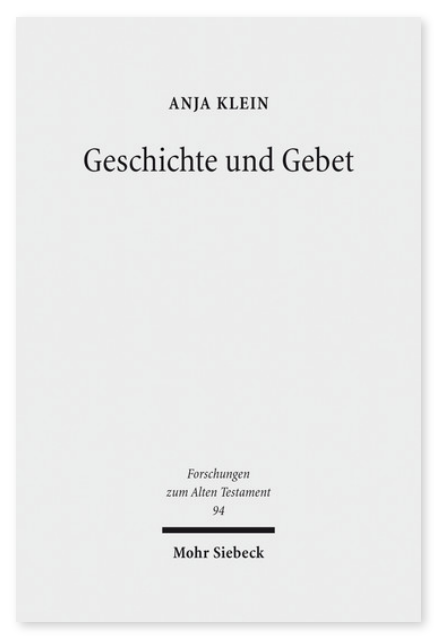

2014. XII, 435 Seiten. FAT 94

SBN 978-3-16-153315-0

DOI 10.1628/978-3-16-153315-0

eBook PDF 144,00€

ISBN 978-3-16-153241-2

Leinen $144,00 €$
Anja Klein legt eine literar- und theologiegeschichtliche Analyse der Geschichtspsalmen Ex 15, Ps 78, 105, 106, 114,135 und 136 vor, die durch einen Ausblick auf Neh 9 ergänzt wird. Neben der redaktionsgeschichtlichen Differenzierung der Texte widmet sie sich in dieser Arbeit der Erhellung der Schriftbezüge in den einzelnen Psalmen. Dabei zeigt sie, dass die Rezeption der biblischen Geschichte mit dem Meerlied Ex 15 im Kontext der erzählenden Überlieferung beginnt und von hier Eingang in den Psalter findet. In der Entstehung von Ex 15 ist eine Durchdringung der Exodusprosa mit Formen und Sprache der Psalmen zu beobachten, die sich als wechselseitiges Auslegungsverhältnis beschreiben lässt und zum literarischen Ausgangspunkt der Verbindung von Geschichte und Gebet wird. Die Texte im Psalmenbuch führen diese Auslegungslinie mit unterschiedlichen Schwerpunkten weiter, so dass sich im literarischen Wachstum ein fortlaufender Diskurs über die biblische Geschichte ergibt. Dieser dynamische Auslegungsvorgang bewegt sich zwischen der ihrerseits gewachsenen Überlieferung der biblischen Geschichte in Pentateuch und Vorderen Propheten und den Psalmen selbst. Er kann als Prozess der Identitätssuche und Identitätsbestimmung des biblischen Judentums beschrieben werden, das sich in diesen Texten der Geschichte mit seinem Gott vergewissert. In ihrer Form als Gebetstexte evozieren die Geschichtspsalmen einen kultischen Rückraum und erlauben die persönliche Aneignung der geschichtlich begründeten Identität im Vollzug des spiritualisierten Gebets.

Anja Klein Geboren 1977; Studium der Ev. Theologie in Bethel, St Andrews und Göttingen; 2008 Promotion; seit 2013 Chancellor's Fellow (Hebrew Bible) an der University of Edinburgh; 2014 Habilitation im Fach Altes Testament an der Universität Göttingen.

Jetzt bestellen:

https://mohrsiebeck.com/buch/geschichte-und-gebet-9783161533150?no_cache=1

order@mohrsiebeck.com

Telefon: +49 (0)7071-923-17

Telefax: +49 (0)7071-51104 